Postprint: Derluyn, H., Janssen, H. Diepens, J., Derome, D., Carmeliet, J. (2007). Hygroscopic behavior of paper and books, Journal of Building Physics, 31 (9): 9-34. DOI: $10.1177 / 1744259107079143$

\title{
Hygroscopic behavior of paper and books
}

\author{
H. Derluyn ${ }^{(\mathrm{a})}$, H. Janssen $^{(\mathrm{b})}$, J. Diepens $^{(\mathrm{c})}$, D. Derome ${ }^{(\mathrm{d})}$ and J. Carmeliet ${ }^{(\mathrm{a}, \mathrm{c})}$ \\ (a) Department of Civil Engineering, Laboratory of Building Physics \\ Katholieke Universiteit Leuven, Kasteelpark Arenberg 40, 3001 Heverlee, Belgium \\ (b) Department of Civil Engineering, Section of Building Physics and Services, \\ Technical University of Denmark, Brovej - Building 118, 2800 Kgs. Lyngby, Denmark \\ (c) Faculty of Building and Architecture, Building Physics and Systems, \\ T.U.Eindhoven, P.O. Box 513, 5600 MB Eindhoven, The Netherlands \\ (d) Building Envelope Performance Laboratory, Department of Building, Civil and \\ Environmental Engineering, Concordia University, 1455 de Maisonneuve blvd West, Montreal, \\ Qc, Canada, H3C $1 M 8$

\begin{abstract}
This paper presents experimental analysis and numerical modeling of hygroscopic moisture buffering by paper and books. First a literature review of moisture transport properties of paper is presented. Experimental work on two paper types includes SEM analysis of the paper structure, determination of sorption isotherms and water vapor permeability measurements. A hysteretic model for paper is presented, which is based on the measurement of the main adsorption and desorption curves. It is shown that the water vapor permeability in a hysteretic model is dependent on the moisture content and not on the relative humidity. Books consist of several paper sheets with air layers between the sheets. To take the air layers into account, a parallel transport model is proposed to determine the effective moisture transport properties of books taking into account the air layers. The dynamic hygroscopic behavior of small book samples was measured. It is shown that, although the water vapor permeability of different paper types can be quite different, the effusivity of a book highly depends on the presence of the air layers and can therefore remain comparable for different paper types.
\end{abstract}

KEY WORDS: paper, book, hygroscopic properties, hysteresis, moisture buffering, effective material properties

\section{INTRODUCTION}

Paper, being made of organic fibers is a hygroscopic material. Books, magazines, newspapers in a room may therefore represent a high potential for moisture buffering, since they are composed of a large set of thin paper layers. Small air layers between the sheets may exist enhancing the water vapor transport into the book and increasing the moisture buffering capacity. Until now, it is not clear which paper surface of a book or magazine is accessible for moisture buffering when exposed to varying indoor air relative humidity. For books with hard cover, only the fore-edge and the top/bottom-edges are accessible for moisture buffering. 
In the past, several experimental and numerical methods and databases have been proposed to determine the moisture transport properties of building materials ([1]-[4], [12], [16]-[17]). However, there is still a need for accurate moisture transport properties of paper, magazines, books and newspapers.

The moisture transport properties of paper itself may vary [7]. The density of paper varies from $610-690 \mathrm{~kg} / \mathrm{m}^{3}$ for newsprint paper to $780 \mathrm{~kg} / \mathrm{m}^{3}$ for fine paper, and up to 1150 $\mathrm{kg} / \mathrm{m}^{3}$ for coated super calendared paper. Newsprint paper thickness may vary from 60 to 80 microns; office paper is around 105 to 110 microns. Porosity of paper can be as high as $70 \%$.

It is reported in literature that, especially, water vapor permeability may vary due to differences in paper structure and surface treatment. The paper structure is determined by the papermaking process, which consists in pulping, bleaching and beating. Pulping is the process in which the wood is broken into wood fibers. We distinguish mechanical and chemical pulping. Bleaching whitens the pulp, enhances brightness and eliminates impurities. The structure of the fiber wall and surface is loosened by the beating process in order to ameliorate the mechanical properties of the paper.

As an example, Figure 1 gives SEM images of a telephone book (TB) paper. We clearly see the fibrous structure of paper. The paper is made of 50 to $100 \%$ recycled fibers and has a matt finishing. Figure 2 gives SEM images of a magazine (M) paper. The paper has a pulp structure. The paper is made of mechanical and chemical pulp, color and fillers, such as talc and calcium carbonate to make the paper smoother. The paper is a machine finished coated paper and has a glossy finishing. The glossy coating gives the paper a more closed surface.

In this study, we first report on the moisture transport properties of paper. Apart from a literature study, we present a model to describe the hysteretic hygroscopic behavior of paper. Two types of papers are measured: a newsprint type paper and a magazine type paper (slightly glossy). In the second part, we present a model to predict the moisture transport properties of books considered as multilayered air-paper systems. The model is based on the properties of the paper itself and on the paper fraction, defined as the ratio of paper volume to the total volume of the book. Focus is on the transport through the foreedge or the top-edge of a book, i.e. with vapor transport parallel to the pages of the book.

\section{HYGROSCOPIC BEHAVIOR OF PAPER}

\section{Theory}

Isothermal water vapor transport is described by

$\frac{\partial w}{\partial t}=\nabla\left(\delta \nabla p_{v}\right)$

with $w$ the moisture content $\left[\mathrm{kg} / \mathrm{m}^{3}\right], t$ the time [s], $\delta$ the water vapor permeability [s] and $p_{v}$ the water vapor pressure [Pa]. Further derivation gives

$\frac{\partial w}{\partial h} \cdot \frac{\partial h}{\partial t}=\xi \cdot \frac{\partial h}{\partial t}=\nabla\left(\frac{\delta_{a}}{\mu} \cdot p_{v s a t} \nabla h\right)$ 
with $\xi$ the moisture capacity $\left[\mathrm{kg} / \mathrm{m}^{3}\right], h$ the relative humidity $(\mathrm{RH})[-], \delta_{a}$ the water vapor permeability of dry air [s], $\mu$ the water vapor resistance factor [-] and $p_{v s a t}$ the saturation water vapor pressure $[\mathrm{Pa}]$. The function describing $w(h)$ is called the sorption isotherm.

A measure of the ability of a material to exchange moisture across its surface, when the humidity changes at its surface, is the moisture effusivity $b_{m}\left[\mathrm{~kg} /\left(\mathrm{m}^{2} \cdot \mathrm{Pa} \cdot \mathrm{s}^{1 / 2}\right)\right]$.

$b_{m}=\frac{\delta}{\sqrt{D_{w}}}=\sqrt{\frac{\xi \delta}{p_{v s a t}}}$

with $D_{w}$ the moisture diffusivity $\left[\mathrm{m}^{2} / \mathrm{s}\right]$.

\section{Literature data}

Sorption isotherm and water vapor permeability data for different types of paper were collected from literature. The data are collected from [6], [10], [12], [13] and [15].

The adsorption isotherms data were fitted using an equation of the van Genuchten type (see in [3])

$w(\phi)=w_{\max }\left(1+(A \cdot \ln (h))^{n}\right)^{n}$

with $A, n$ parameters and $w_{\max }$ the moisture content at $h=1$. We use the common assumption that $m$ is given by $m=(1-n) / n$. The water vapor permeability data were fitted using the equation

$\delta(h)=\frac{\delta_{a}}{\mu(h)} \quad$ with $\quad \mu(h)=\frac{1}{a+b \cdot e^{c h}}$

Tables 1 and 2 give the fitted parameters for the different types of papers. Figure 3(a) gives the adsorption isotherms $w(h)$. Different paper types show different ranges of moisture content, but the shape of the curves is rather similar. Figure 3(b) gives the moisture capacity $\partial w / \partial h$. The variation between the different types of paper is rather low. At low relative humidity $(<60 \% \mathrm{RH})$ the moisture capacity is almost constant. The moisture capacity increases quickly above $60 \%$ RH. Figure 3(c) gives the vapor resistance factor for different types of paper. The dry water vapor resistance factor $\mu_{d r y}$ differs a lot for the different types of paper. $\mu_{d r y}$ varies from 50 for regular wallpaper to more than 8000 for a vinyl paper. Even between different types of vinyl paper, $\mu_{d r y}$ varies a lot (from 200 to 8000). For all paper types, the water vapor resistance factor decreases at higher relative humidity and differences between different types become less important.

\section{Material property measurements}

Two materials are measured: a newsprint type paper, referred to as telephone book (TB) paper, and a magazine type paper (slightly glossy), referred to as magazine (M) paper. The dry density was determined measuring the dry weight and the thickness of a paper sheet. The thickness was determined using a micro-meter and also from SEM images. The data are summarized in Table 3. 


\section{Sorption isotherm}

The isothermal sorption curves are determined by conditioning samples in a dessicator with saturated salt solutions at constant temperature $\left(23^{\circ} \mathrm{C}\right)$. The samples consisting of several paper sheets were initially dried in an oven of $50^{\circ} \mathrm{C}$ and $3 \% \mathrm{RH}$. First, the main adsorption isotherm was determined. After attaining equilibrium, the specimens were sequentially placed at lower relative humidities to determine the (primary) desorption curves. Figure 4 gives the main adsorption and primary desorption data for the TB paper and $\mathrm{M}$ paper. The main adsorption isotherm is fitted using an equation (introduced by Hansen, see in [3]) of the form of Equation (4) with $n=1, \mathrm{~A}=-1 / A_{a d}$ and $m=-1 / n_{a d} ; \mathrm{A}_{\text {ad }}$ and $\mathrm{n}_{\mathrm{ad}}$ are parameters. In the same way the main desorption isotherm is fitted, using the parameters $A_{d e}$ and $n_{d e}$. The values for the parameters are given in Table 3. In Figure 5(a), we observe that the moisture capacity for TB paper and M paper is comparable with the data from literature. Both kinds of paper show a similar moisture capacity.

\section{Water vapor permeability measurements}

The water vapor permeability is measured at three different RH ranges using the dry/wet cup test method (12-54\% RH, 54-86\% RH, 86-97\% RH). The specimens consist of a set of paper sheets, which are highly compressed to limit the possibility of air layers in between the sheets. Based on the literature review and a first set of dry/wet cup test data, the number of sheets was chosen in order to have specimens with an equivalent air layer thickness $\mu d$ (with $d$ the thickness) larger than $0.2 \mathrm{~m}$. According to EN ISO 12572:2001 [8], when meeting this condition, no correction for the resistance of the air gap between the sample and the saturated salt solution is required. As a result, the telephone book specimens have 64 sheets, and the magazine specimens 52.

Two methods are applied to determine the nonlinear water vapor permeability from the measured steady state vapor flow $g_{v}$.

In the first method the water vapor resistance factor is assumed to be constant in the RH range $\left[h_{1}, h_{2}\right]$, where $h_{1}$ and $h_{2}$ are the RH's on each side of the sample. The water vapor resistance factor at the average relative humidity $\left(h_{1}+h_{2}\right) / 2$ is then determined by

$g_{v}=-\delta \frac{\Delta p_{v}}{d}=\frac{1}{\mu} \frac{\delta_{a} \cdot p_{v s a t} \cdot\left(h_{2}-h_{1}\right)}{d}$

with $d$ the thickness of the test sample [m]. Figure 6 gives the water vapor resistance factor at the three RH's. In a second step, we fit the nonlinear water vapor resistance factor using Equation (5). The parameters are given in Table 3. We observe on Figure 5 that the magazine paper is about 5 times more vapor tight than the telephone book paper. This difference can be explained by the higher density of the magazine paper, the pulp paper structure, the lower porosity and the effect of the finish coating.

In the second more accurate method, we assume the water vapor resistance factor to be nonlinear. Vapor transport is then given by

$g_{v}=-\delta(h) \frac{\partial p_{v}}{\partial x}$

Integrating by parts, we get

$\int_{0}^{d} g_{v} \cdot \mathrm{d} x=\int_{h_{1}}^{h_{2}} \delta(h) \cdot p_{v s a t} \mathrm{~d} h$. 
Knowing that, in steady state, $g_{v}$ is constant and using Equation (5) for the nonlinear water vapor permeability, we get after integration

$g_{v} d=p_{v s a t} \delta_{a}\left[a\left(h_{2}-h_{1}\right)+\frac{b}{c}\left(e^{c h_{2}}-e^{c h_{1}}\right)\right]$

The parameters $a, b$ and $c$ can be determined based on the three measurements of the vapor flow (see Table 3 ).

Figures 6(a) and 6(b) compare the water vapor resistance factor as determined by the two methods for TB and $\mathrm{M}$ paper. We observe that method 1 under predicts the water vapor resistance factors at higher RH. For TB paper, the relative difference $\left(\mu_{2}-\mu_{1}\right) / \mu_{2}$ given in dotted line increases to $15 \%$ at $\mathrm{RH}=1$, while for $\mathrm{M}$ paper, which is more vapor tight, the difference increases to $23 \%$. Figure 5(b) compares the water vapor resistance factor of TB paper and $\mathrm{M}$ paper with data from literature. TB paper is rather vapor open and the dependence on $\mathrm{RH}$ is analogue to the literature data. M paper is quite vapor tight and remains more vapor tight with increasing $\mathrm{RH}$ compared to the literature data.

\section{Hysteresis model for paper}

We present a model for hysteretic hygroscopic behavior [5], which is based on the concept originally presented by Mualem [14] for soils. To describe the history of an adsorption/desorption process, we use the Enderby's notation. For example, $w\left(h_{1} h_{2} h_{3}\right)$ describes a loading protocol going from a lower RH $h_{1}$ up to $h_{2}$ and again down to $h_{3}$. In adsorption, we assume that all possible sorption sites in the porous material are accessible. The possible sorption sites are distributed according to a function $f(h)$. A sorption site will be filled above a critical RH $\psi$. The main adsorption curve is then given by

$$
w\left({ }_{0}^{\psi}\right)=w_{a d}(\psi)=\int_{0}^{\psi} f(h) d h=F(\psi)
$$

or the main adsorption curve equals the integral of the distribution $f(h)$. In desorption, a sorption site can only become unfilled when the pore entry of the pore becomes unfilled. We assume that different pores do not interact with each other. The accessibility to the sorption sites is described by a normalized accessibility function $a(h)$. Sorption processes can be schematically represented in a $f$ - $a$ space. The $f$-axis gives the possible sorption sites, while the ordinate represents the accessibility function. Integration in the $f-a$ space makes it possible to calculate the moisture content by multiplying the possible filled sorption sites with their accessibility.

The main adsorption curve is given by (see Figure 7(a))

$$
w\left({ }_{0}{ }^{\psi}\right)=w_{a d}(\psi)=\int_{0}^{\psi} f(h) d h \int_{0}^{1} a(h) d h=F(\psi) A(1)=F(\psi)
$$

The integral over the total range of the accessibility function (from 0 to 1 ) indicates that all pores are accessible during adsorption. Since $a(h)$ is normalized, $A(1)=1$. During desorption to a relative humidity $\psi$, the pores accessible between $\phi_{\max }$ and $\psi$ will desorb. According to Figure 7(b) the moisture content during main desorption is given by 
$w\left(h_{\max }{ }_{\psi}\right)=w_{d e}(\psi)=w_{\text {max }}-\left(w_{\text {max }}-w_{a d}(\psi)\right) \int_{\psi}^{1} a(h) d h$

$$
\begin{aligned}
& \text { or } \\
& \begin{aligned}
w\left(h_{\max }\right)=w_{d e}(\psi) & =w_{\max }-\left(w_{\max }-w_{a d}(\psi)\right)(1-A(\psi)) \\
& =w_{a d}(\psi)+\left(w_{\max }-w_{a d}(\psi)\right) A(\psi)
\end{aligned}
\end{aligned}
$$

The equation shows that the integral of the accessibility function $A(\psi)$ can be determined from the main adsorption and main desorption curve, or

$$
A(\psi)=\frac{w_{d e}(\psi)-w_{a d}(\psi)}{w_{\max }-w_{a d}(\psi)}
$$

The process of primary desorption (desorption from the main adsorption curve) is given in Figure 7(c). Integration in the $f-a$ space gives

$$
w\left(\begin{array}{c}
h_{1} \\
0
\end{array}\right)=w_{a d}(\psi)+\left(w_{a d}\left(h_{1}\right)-w_{a d}(\psi)\right) A(\psi)
$$

The process of primary adsorption (adsorption from the main desorption curve) is given in Figure 7(d). Integration in the $f-a$ space gives

$w\left({ }_{0}^{h_{\max }} h_{1} \psi\right)=w_{a d}(\psi)+\left(w_{\max }-w_{a d}(\psi)\right) A\left(h_{1}\right)$

Formulas for adsorption or desorption after a series of alternating processes of adsorption or desorption can also be derived by integrating in the $f$ - $a$ space. Figures 8(a) and 8(b) compare the measured and calculated primary desorption curves for TB and M paper. The parameters used to describe the main adsorption and desorption curves are given in Table 3. We observe in Figures 8(a) and 8(b) that at lower RH the primary desorption curves are well described. At higher $\mathrm{RH}$, there is less agreement between measurements and the hysteresis model. Nevertheless, the advantage of the present hysteresis model is that only the main adsorption and desorption curves are needed.

\section{Water vapor permeability}

The nonlinear water vapor permeability for non-hysteretic materials is commonly described as function of the relative humidity (see Equation (5)). The increase of the water vapor permeability at high relative humidity is commonly explained by the fact that microscopic liquid water transport in filled pores enhances the apparent water vapor transport. This means that the apparent water vapor diffusion coefficient should not depend on the relative humidity, but on the degree of saturation $S_{l}=w(h) / w_{\max }$. The equation for the water vapor permeability then reads

$$
\delta\left(S_{l}\right)=\frac{\delta_{a}}{\tau} \phi_{0} f\left(S_{l}\right)=\frac{\delta_{a}}{\mu\left(S_{l}\right)}
$$

with $\tau$ the tortuosity and $\phi_{0}$ the open porosity. In the performed cup tests, the water vapor resistance factor is measured in the adsorption regime, since the specimens were dried first and then installed into the cup (this is a slight deviation of the EN ISO standard in order to know the sorption regime of the measurement). The measurement data are fitted by the function $\mu_{a d}(h)$ using Equation (5). Using the inverse of the main adsorption isotherm $w_{a d}(h)$, we get

$\mu\left(S_{l}\right)=\mu_{a d}\left[w_{a d}^{-1}\left(S_{l}\right)\right]$ 
As example, we analyze the material response during a $\mathrm{RH}$ loading protocol as given in Figure (9). The material is TB paper. In figures 10(a)-(d) the hysteretic loops as well as the main adsorption and desorption curves are given for respectively: the sorption isotherm (a), the water vapor resistance factor (b), the moisture capacity (c) and effusivity (d). We observe that after the cycling, the material behavior evolves to an almost single curve. For the sorption isotherm and water vapor resistance factor, this curve is an intermediate curve between main adsorption and desorption curve. The hysteretic material is thus more vapor open than the material in adsorption, but more vapor tight than the material in desorption. We observe in Figure 10(c) that the hysteretic material has after cycling a slightly lower moisture capacity than in adsorption, but that the moisture capacity is much lower than in desorption. In Figure 10(d), we see that with cyclic loading, the effusivity comes close to the adsorption effusivity. This is logical, since hysteresis leads to two opposite effects: the material becomes more vapor open than in the adsorption state, but has less moisture capacity than in adsorption, which means the effusivity might not change so much.

When we simulate the main desorption process, desorption transport properties should be chosen. We analyze what the influence is on the results when adsorption properties are used instead of desorption properties. We distinguish three cases: (1) desorption transport properties, which is the reference case, (2) adsorption transport properties (adsorption case), (3) desorption moisture capacity, but adsorption water vapor resistance factor (mixed case). Figure 11(a) gives the effusivity for the three cases. We observe that the mixed case under predicts the desorption effusivity. With adsorption properties, the effusivity is over predicted at high RH and under predicted at lower RH.

As example, we simulate the desorption process for a step change from 0.8 to $0.5 \mathrm{RH}$. The water vapor transport is one dimensional. The water vapor surface coefficient $\beta=$ $5.10^{-8} \mathrm{~s} / \mathrm{m}$. The moisture transport properties of TB paper are used. Figure 11(b) gives the moisture release $\Delta w=w_{0}-w$, with $w_{0}$ the initial moisture content at $\mathrm{RH}=0.8$. The adsorption and mixed case under predict $\Delta w$, since the effusivity is under predicted in the RH range $[0.5,0.8]$.

\section{MODELLING OF THE HYGROSCOPIC BEHAVIOR OF BOOKS}

\section{Hygroscopic behavior of books}

A book is defined as a number of sheets of paper with air layers in between. The total volume of the book is $V_{\text {tot }}=V_{a}+V_{p}(\mathrm{a}=$ air layer; $\mathrm{p}=$ paper layer $)$. The paper fractions in the book $\Psi_{\mathrm{p}}[-]$ and $\Psi_{\mathrm{a}}[-]$ are defined as

$\Psi_{p}=\frac{V_{p}}{V_{t o t}} \quad, \quad \Psi_{a}=\frac{V_{t o t}-V_{p}}{V_{t o t}}=1-\Psi_{p}$

The hygroscopic behavior is measured exposing book specimens to a step change in RH. The experimental set-up of the Building Physics and Systems Unit of TU.Eindhoven is used [9]. A book specimen consists of a number of paper sheets $\left(0.05 \mathrm{x} 0.05 \mathrm{~m}^{2}\right)$, which 
are placed in a sample holder of the form of a small box with five plexiglass sides. The open side, with all the sheet edges regularly spaced, mimics the fore-edge of a book. Two paper fractions for magazine book are used: high $\left(\Psi_{p}=0.86\right)$ and low $\left(\Psi_{p}=0.51\right)$. Also a telephone book specimen with a paper fraction $\Psi_{p}=0.9$ is measured. After reaching equilibrium at $\mathrm{RH}=0.54$, a step change from 0.54 to 0.795 is imposed. Moisture uptake is possible only through the open side, which means uptake parallel to the paper sheets. Figure 12 gives the moisture uptake $\Delta w=w-w_{0}$ versus time for the three book specimens, with $w_{0}$ the initial moisture content at $\mathrm{RH}=0.54$. Although the magazine paper is more vapor tight than the telephone book paper, the two book specimen with high paper fraction show a similar uptake behavior. The moisture uptake of the low paper fraction book is lower than the high paper fraction book. The low paper fraction book will however attain equilibrium faster compared to the high paper fraction book. This means that, due to the presence of air layers between the paper sheets, the low paper fraction book is characterized by a higher effective permeability and lower effective moisture capacity compared to high paper fraction book specimens.

In the next section, we formulate a model to predict the effective moisture transport properties of books. The model will then be used to explain the comparable behavior of the high paper fraction magazine and the telephone book specimens, although the papers of each book show quite a different water vapor permeability.

\section{Effective moisture transport properties of books}

We assume the paper to be a homogeneous and isotropic material.

\section{Effective density of book}

The dry density of a book $\rho_{b}\left[\mathrm{~kg} / \mathrm{m}^{3}\right]$ is given by:

$\rho_{b}=\rho_{p} \cdot \Psi_{p}+\rho_{a} \cdot \Psi_{a}=\rho_{p} \cdot \Psi_{p}+\left(1-\Psi_{p}\right) \cdot \rho_{a}$

with $\rho_{p}$ the dry density of the paper and $\rho_{a}$ the density of air.

\section{Effective moisture capacity of book}

The moisture content of a sheet of paper is defined as

$w_{p}=\rho_{l} \cdot \phi_{0} \cdot S_{l}$

with $\rho_{l}$ the density of the liquid, $\varphi_{0}$ the open porosity of the paper, and $S_{l}$ the degree of saturation. Since the volumetric moisture capacity of air is around 10000 times smaller than the moisture capacity of paper, the water vapor present in the air layer can be neglected. The moisture content of book $w_{b}$ can then be written as

$w_{b}=\rho_{l} \cdot \phi_{0} \cdot S_{l} \cdot \Psi_{p}=\Psi_{p} \cdot w_{p}$

The effective moisture capacity of a book $\xi_{b}$ is given by differentiating Equation (22)

with respect to $\mathrm{RH}$

$\xi_{b}=\frac{\delta w_{b}}{\delta h}=\frac{\delta w_{b}}{\delta w_{p}} \cdot \frac{\delta w_{p}}{\delta h}=\Psi_{p} \cdot \xi_{p}$ 
Effective water vapor permeability of book [7]

A book is considered as a periodic system of paper sheets and air layers. We define a representative volume (REV) consisting of a half layer of paper and a half layer of air (Figure 13(a)).

In this REV, two different paths for water vapor transport exist (see Figure 13(a)). The first path describes water vapor transport in paper normal to the fore-edge of the book. In the second path, water vapor is transported parallel to the paper sheets through the air layer towards the inner part of the book, and then adsorbed by paper in a direction normal to the sheet. Air is characterized by a high water vapor permeability, but very low moisture capacity. This means that the water vapor transported via the air layer is not buffered by the air layer itself, but will be almost immediately buffered by the paper sheets. Due to the limited thickness of paper, the moisture is quickly redistributed over the thickness and a one-dimensional moisture front is attained: the moisture front advances parallel to the fore-edge of the book during moisture uptake. So, two different transport paths exist building up the same moisture front in the paper sheet. This means, that in a first approximation, we can model the water vapor transport in book as a parallel system. The water vapor permeability of this parallel system is given by

$\delta_{b}=\Psi_{p} \cdot \delta_{p}+\Psi_{a} \cdot \delta_{a}$

with $\delta_{b}, \delta_{p}$ and $\delta_{a}$ respectively the water vapor permeability of book, paper and air. We now introduce a factor $\alpha$, so that

$\delta_{b}\left(h, \Psi_{p}\right)=\alpha\left(h, \Psi_{p}\right) \delta_{p}(h)$

From Equation (24) and (25), we get

$\alpha\left(h, \Psi_{p}\right)=\mu_{p}(h)-\left(\mu_{p}(h)-1\right) \cdot \Psi_{p}$

Effective moisture buffering capacity of book

The effective effusivity of a book is then equal to

$b_{m, b}=\sqrt{\frac{\xi_{b} \delta_{b}}{p_{v s a t}}}=\sqrt{\frac{\Psi_{p} \xi_{p} \alpha \delta_{p}}{p_{v s a t}}}=\sqrt{\Psi_{p} \alpha} \cdot \sqrt{\frac{\xi_{p} \delta_{p}}{p_{v, \text { sat }}}}$

or

$b_{m, b}=\chi b_{m, p}$

The factor $\chi$ is dependent on $\mathrm{RH}$ and the paper fraction.

We remark that it can be expected that the vapor permeability of paper is not isotropic, especially when the surface has a glossy coating, as for the magazine paper. However, due to the presence of air layers in a book, the vapor flow through the air layers is dominant compared to the flow normal to the paper edge. Therefore only a small error is introduced assuming isotropic behavior.

\section{Validation}

To validate Equations (24) or (25) and (26), we simulate the two-dimensional water vapor transport in the REV taking into account as well vapor transport normal to the edge of the paper as vapor transport in the air layers. The simulation model HAMFEM is used 
[11]. The loading consists in a stepwise adsorption from 0.54 to $0.795 \mathrm{RH}$ normal to the fore-edge of the book. The surface mass transfer coefficient $\beta$ equals $5.10^{-8} \mathrm{~s} / \mathrm{m}$. No flow conditions are considered at all other sides of the REV. The thickness of one sheet of paper is $60 \mu \mathrm{m}$. The thickness of the air layer is calculated from a paper fraction of $\Psi_{p}=$ 0.6. For the paper, the material properties of paper wallpaper 1 of the literature review are taken (see Table 1 and 2). For air, the sorption curve is given by the ideal gas law and the water vapor permeability is taken to be the water vapor permeability of stagnant air: $\delta_{a}=$ $1.92 \cdot 10^{-10} \mathrm{~s}$. No air transport is considered. The temperature is constant at $23^{\circ} \mathrm{C}$. Figure 13(b) gives the time evolution of the average moisture content of the REV calculated with the 2D model. This result is compared with a 1D calculation using effective transport properties as given by Equations (23) and (24). A good agreement is obtained with a maximal error less than $0.15 \%$. Simulations at other paper fractions give comparable good agreement.

For experimental validation of the proposed book model, controlled moisture uptake experiments on small book specimens of the magazine paper are performed. The experimental set-up of the Building Physics and Systems Unit of TU.Eindhoven is used [9]. A book specimen with a high paper fraction $\left(\Psi_{p}=0.88\right)$ and one with a low paper fraction $\left(\Psi_{p}=0.55\right)$ are tested. The dimension of the side open to the environment measures $0.04 \times 0.04 \mathrm{~m}^{2}$. The depth of the specimens is limited $(0.02 \mathrm{~m})$ in order the specimens will reach equilibrium in short time. To obtain a uniform spacing between the paper sheets of the low paper fraction book specimen, metal sheets with a thickness of 50 $\mu \mathrm{m}$ are placed between the paper sheets. After pressing the specimen highly between plexiglass plates, the lateral and bottom sides of the specimens are made vapor tight by applying a polyurethane sealant. After drying of the sealant, the metal paper sheets are removed. The specimens are initially dried and then exposed to a $\mathrm{RH}$ of 0.54 until equilibrium is attained. After reaching the equilibrium state, a step change from 0.54 to 0.795 is imposed. Figure 14 gives the measurement results of the moisture uptake $\Delta w=w$ $w_{0}$. Using the developed book model, the moisture uptake curves are simulated using a surface mass transfer coefficient $\beta$ of $2.10^{-7} \mathrm{~s} / \mathrm{m}$ for the high paper fraction book and a value of $1.10^{-8} \mathrm{~s} / \mathrm{m}$ for the low paper fraction book. The lower transfer coefficient for the low paper fraction paper is attributed to the unevenness of the exposed surface of the low paper fraction specimen (we did not flatten the surface since this would influence the distance between the sheets). The transport properties of magazine paper for adsorption are used. A good agreement between measurement and simulation is observed.

\section{Discussion}

Finally, we explain the measurements of Figure 12 using the book model. From equations (27) and (28), we evaluate the effusivity of magazine and telephone book for the given paper fractions. Figure 15 gives the effusivity for magazine at two paper fractions $\left(\Psi_{p}=\right.$ $\left.0.86, \Psi_{p}=0.51\right)$ and for telephone book at a paper fraction $\Psi_{p}=0.9$. We observe that magazine and telephone book at high paper fraction have comparable effusivities although $M$ paper is much more vapor tight than TB paper. The high vapor resistance factor of $\mathrm{M}$ paper is compensated totally by the very high vapor permeability of the air layers. This explains the comparable moisture uptake as observed in the experiment (see 
Figure 12). The effusivity of the magazine at lower paper fraction is higher than the effusivity at high paper fraction, which explains the fast moisture uptake for the low paper fraction book as observed in Figure 12. However, the total moisture uptake will be lower than for the high paper fraction book since the total moisture content is dependent on the paper fraction as given by Equation (22).

\section{CONCLUSIONS}

In this paper, the moisture buffering of paper and books normal to the fore-edge is analyzed. The literature review shows that different paper types show comparable moisture capacity, but may show quite different water vapor permeability. Paper shows hysteresis and a hysteresis model is presented, which is based on the knowledge of the adsorption and desorption isotherm. We found that the water vapor permeability of a hygroscopic material showing hysteresis, like paper, depends on the moisture content and not on the relative humidity. Hysteresis leads to two opposite effects: the material becomes more vapor open, but shows less moisture capacity, which means the effusivity might not change so much. It was also indicated that using desorption instead of adsorption moisture properties, the effusivity is over-predicted.

Experiments on book specimens show that the air layers between the paper sheets play an important role. Vapor transport through the air layer leads to an increase of the effective vapor permeability. The total amount of water vapor uptake however reduces due to the reduction of the paper volume at low paper fractions. The experiments further show that although the water vapor permeability of paper can be quite different, the moisture buffering capacity or effusivity of a book can remain comparable due to the presence of these vapor open air layers. It was further found that the two-dimensional moisture transport in a book considered as a multilayered air-paper system can be modeled by a one-dimensional parallel transport system with a moisture capacity equal to the moisture capacity of the paper sheets. The parallel system consists of a transport path in paper normal to the fore-edge of the book and a transport path through the air layers towards the paper. The proposed homogeneous system stems from the fact that the air between the paper layers has almost no moisture capacity while the paper is in comparison a large moisture sink.

\section{REFERENCES}

1. Carmeliet, J., Descamps, F., Houvenaghel, G. (1999). Multiscale network model for simulating liquid water and water vapour transfer properties of porous materials, Transport in Porous Media, 35: 67-88.

2. Carmeliet, J. and Roels, S. (2001). Determination of the Isothermal Moisture Transport Properties of Porous building Materials, Journal of Thermal Envelope and Building Science, 24: 183-210. 
3. Carmeliet, J. and Roels, S. (2002). Determination of the moisture capacity of porous building materials, Journal of Thermal Envelope and Building Science, 25(3): 209237.

4. Carmeliet, J., Hens, H., Roels, S., Adan, O., Brocken, H., Cerny, R., Pavlik, Z., Hall, C., Kumaran, K., Pel, L. (2004). Determination of the Liquid Water Diffusivity from Transient Moisture Transfer Experiments, Journal of Thermal Envelope and Building Science, 27(4): 277-305.

5. Carmeliet, J., de Wit, M. and Janssen, H. (2005). Hysteresis and moisture buffering of wood, Symposium of Building Physics in the Nordic Countries, June 13-15 2005, Reykjavik, Iceland, pp.55-62.

6. Chatterjee, S.G. (2001). Comparison of Domain and Similarity Models for Characterizing Moisture Sorption Equilibria of Paper, Industrial and Engineering Chemical Research, 40: 188-194.

7. Derluyn, H. (2006). Role of textiles and paper for stabilizing the indoor environment, M.Sc.thesis, Katholieke Universiteit Leuven, Leuven, Belgium. (http://www.kuleuven.be/bwf/eng/teaching_msctheses)

8. EN ISO 12572. (2001). Hygrothermal performance of building materials and products - Determination of water vapour transmission properties.

9. Goossens, E. (2003). Moisture transfer properties of coated gypsum, $\mathrm{PhD}$-thesis, TU/e, Eindhoven, The Netherlands.

10. Gupta, H., Chatterjee, S.G. (2003). Parallel Diffusion of Moisture in Paper, Part 1: Steady-State Conditions, Industrial and Engineering Chemical Research, 42: 65826592.

11. Janssen, H., Carmeliet, J., Hens, H. (2004). The influence of soil moisture transfer on building heat loss via the ground, Buildings and Environment, 39(7): 825-836.

12. Kumaran, K. (1996). International Energy Agency, Condensation and energy Catalogue of material properties, Report Annex 24 Volume 3, Energy conservation in buildings.

13. Motta Lima, O.C., Monteiro, A.S., Pereira, N.C., Mendes, E.S. (2003). Moisture Equilibrium Isotherms for a Commercial Liquid Package Paper, Drying Technology, 21(10): 1909-1922.

14. Mualem, Y. (1974). A conceptual model of hysteresis, Water Resources research, 10(3): 514-520.

15. Ramarao, B.V., Massoquete, A., Lavrykov, S. and Ramaswamy, S. (2003). Moisture Diffusion Inside Paper Materials in the Hygroscopic Range and Characteristics of Diffusivity Parameters, Drying Technology, 21(10): 2007-2056.

16. Roels, S., Carmeliet, J., Hens, H., Adan, O., Brocken, H., Cerny, R., Pavlik, Z., Ellis, A.T., Hall, C., Kumaran, K., Pel, L., Plagge, R. (2004). A comparison of Different Techniques to Quantify Moisture Content Profiles in Porous Building Materials, Journal of Thermal Envelope and Building Science, 27(4): 261-276.

17. Roels, S., Carmeliet, J., Hens, H., Adan, O., Brocken, H., Cerny, R., Pavlik, Z., Hall, C., Kumaran, K., Pel, L., Plagge, R. (2004). Interlaboratory Comparison of Hygric Properties of Porous Building Materials, Journal of Thermal Envelope and Building Science, 27(4): 307-325. 
Table 1. Parameters for adsorption isotherms for different types of paper.

\begin{tabular}{ccccc}
\hline & $w_{\max }\left(\mathrm{kg} / \mathrm{m}^{3}\right)$ & density $\left(\mathrm{kg} / \mathrm{m}^{3}\right)$ & $A$ & $n$ \\
\hline periodical $^{(1)}$ & 174 & 671 & -69.28 & 1.47 \\
newspaper $^{(1)}$ & 707 & 729 & -332.92 & 1.45 \\
textile wallpaper 1 $^{(1)}$ & 214 & 685 & -53.08 & 1.50 \\
textile wallpaper 2 $^{(1)}$ & 375 & 476 & -236.90 & 1.58 \\
vinyl wallpaper 1 $^{(1)}$ & 658 & 665 & -74.86 & 1.99 \\
vinyl wallpaper 2 $^{(1)}$ & 159 & 471 & -132.11 & 1.64 \\
paper wallpaper 1 $^{(1)}$ & 147 & 600 & -52.87 & 1.60 \\
paper wallpaper 2 $^{(1)}$ & 270 & 539 & -242.95 & 1.54 \\
Bleached kraft paperboard (BKP) $^{(2)}$ & 224 & 663 & -63.00 & 1.39 \\
KLABIN-PR KLAPAK $^{(3)}$ & 117 & 353 & -40.00 & 1.47 \\
(commercial liquid package paper) & & & & \\
\hline
\end{tabular}

(1) Kumaran (1996)

${ }^{(2)}$ Gupta \& Chatterjee (2003)

${ }^{(3)}$ Motta Lima et al. (2003)

Table 2. The parameters for the water vapor resistance factor for different types of paper.

\begin{tabular}{|c|c|c|c|}
\hline & $a$ & $b$ & $c$ \\
\hline newspaper ${ }^{(1)}$ & 0.0275 & l & l \\
\hline textile wallpaper $1^{(2)}$ & 0.0014 & $8.1710^{-8}$ & 17.5 \\
\hline textile wallpaper $2^{(2)}$ & 0.004 & $2.0510^{-6}$ & 13 \\
\hline vinyl wallpaper $1^{(2)}$ & 0.000121 & $210^{-7}$ & 12 \\
\hline vinyl wallpaper $2^{(2)}$ & 0.0048 & $9.4610^{-7}$ & 12.68 \\
\hline paper wallpaper $1^{(2)}$ & 0.0075 & $610^{-5}$ & 7 \\
\hline paper wallpaper $2^{(2)}$ & 0.0170 & $1.9410^{-6}$ & 13 \\
\hline
\end{tabular}

(1) Ramarao et al. (2003)

${ }^{\text {(2) Kumaran (1996) }}$ 
Table 3. Material properties for telephone book paper and magazine paper

Telephone book paper

\section{General}

thickness $(\mu \mathrm{m})$

dry weight $\left(\mathrm{kg} / \mathrm{m}^{2}\right)$

dry density $\left(\mathrm{kg} / \mathrm{m}^{3}\right)$

Sorption isotherm

$w_{\max }\left(\mathrm{kg} / \mathrm{m}^{3}\right)$

$A_{\text {ad }}$

$n_{a d}$

$A_{d e}$

$n_{d e}$

Water vapor permeability

method 1

a

$b$

$c$

method 2

a

b
54

0.0372

690

165

0.19

1.12

1.66

0.45

0.0092

$6.4310^{-5}$

7.14

0.00919

$5.6210^{-5}$

7.12
Magazine paper

65

0.0545

840

149

0.20

1.03

1.63

0.42

0.00167

$7.5710^{-7}$

11

0.00167

$5.7410^{-7}$

11 
(a)

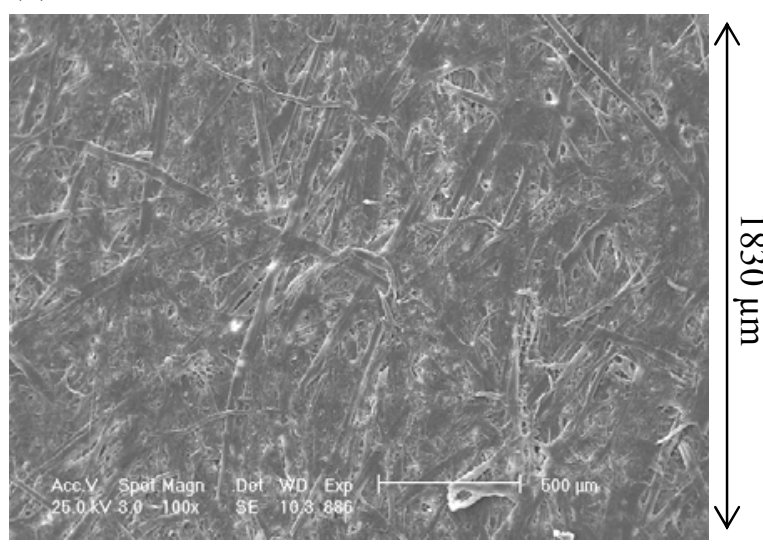

(b)

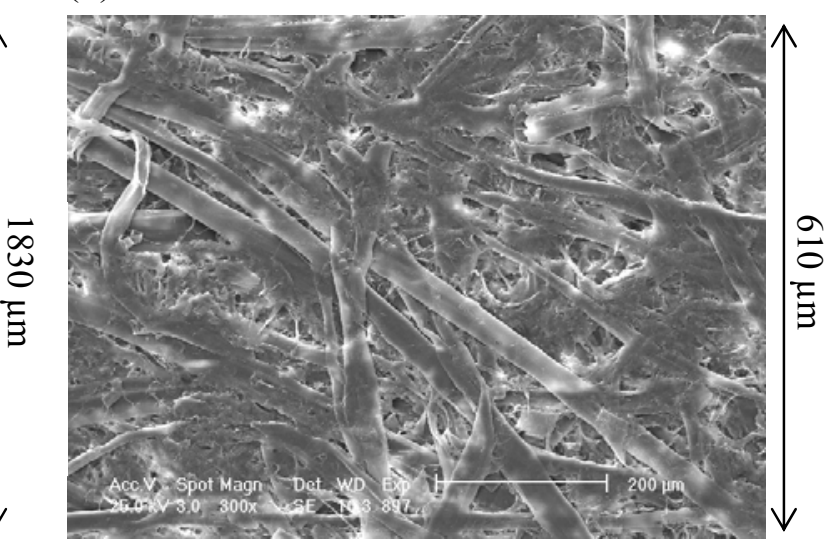

Figure 1. (a-b) SEM images of top surface of telephone book (TB) paper. 
(a)

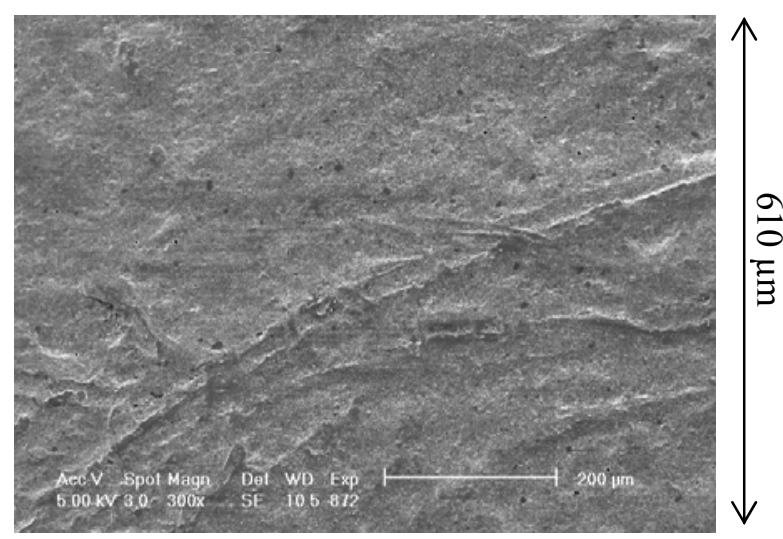

(b)

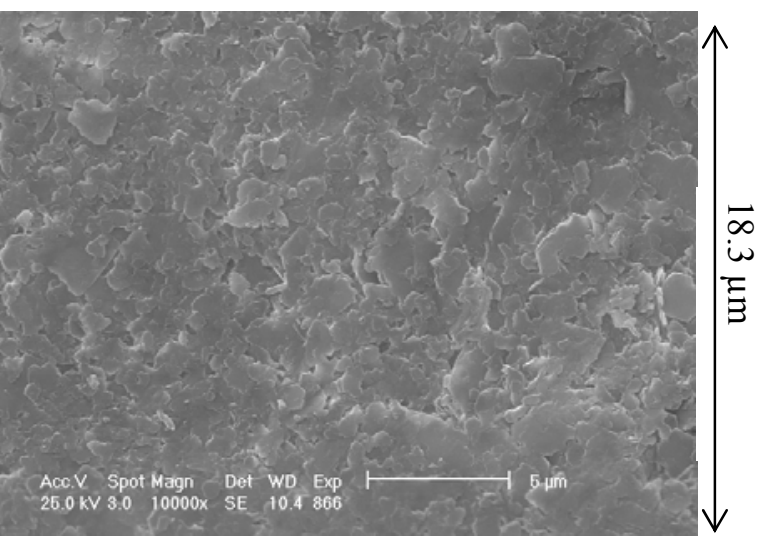

Figure 2. (a-b) SEM images of top surface of magazine (M) paper. 
(a)

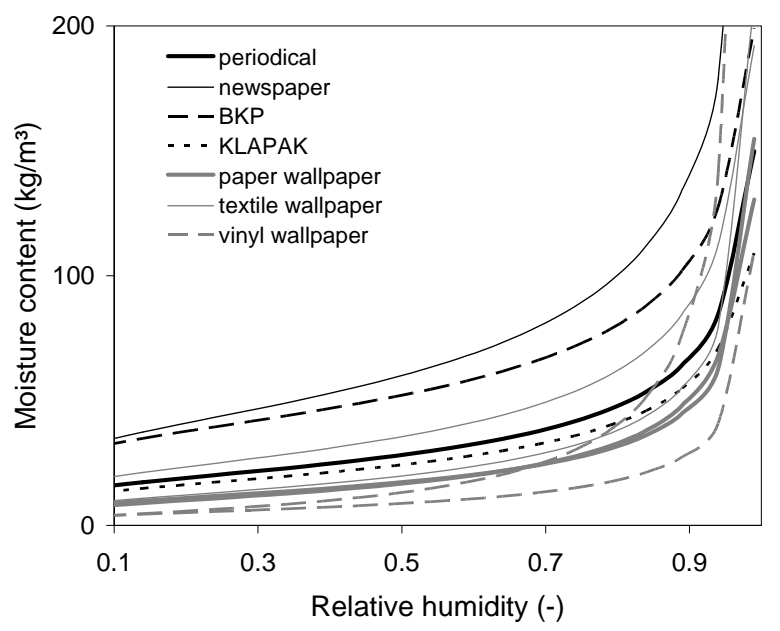

(b)

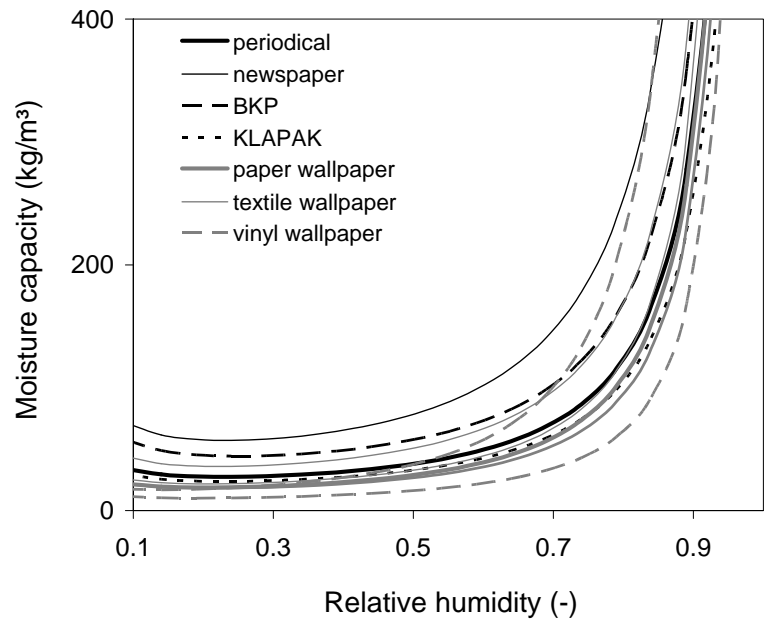

(c)

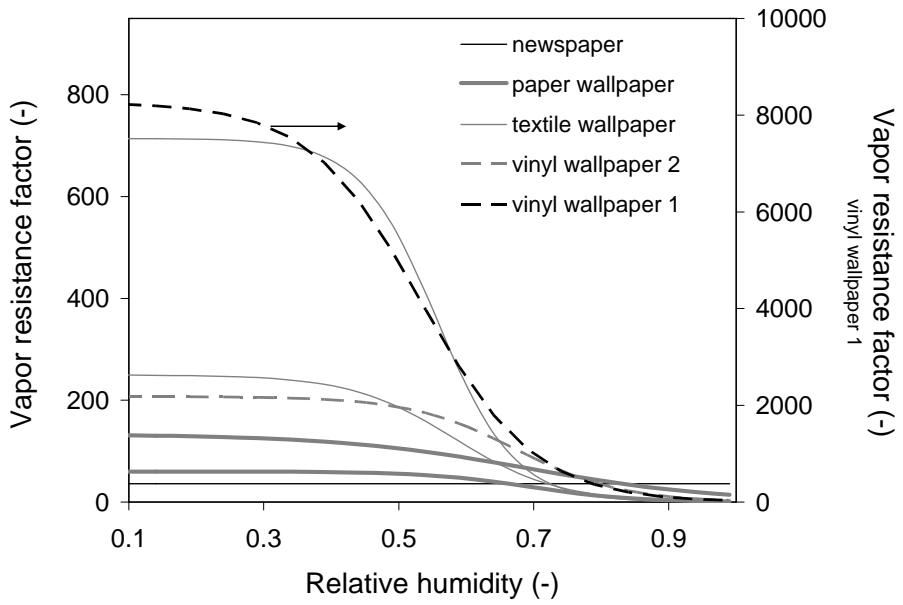

Figure 3. Moisture transport properties of different paper types. 
(a)

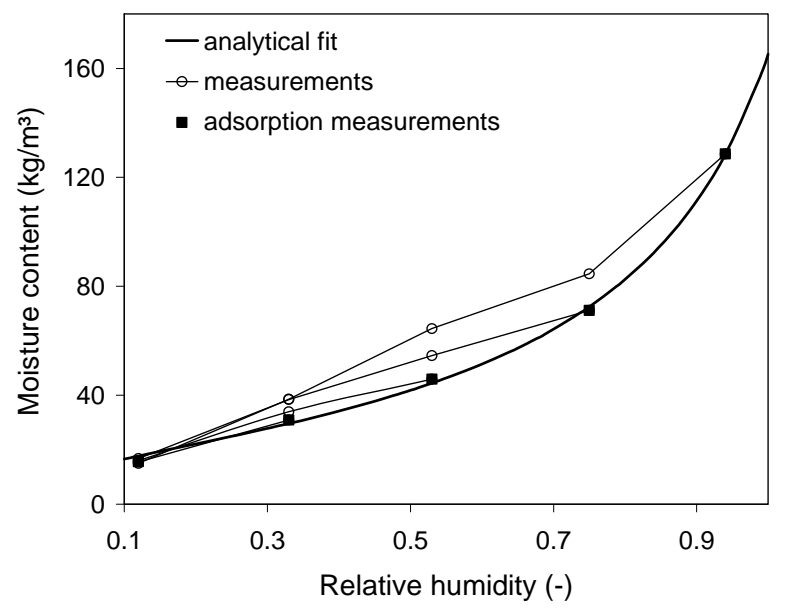

(b)

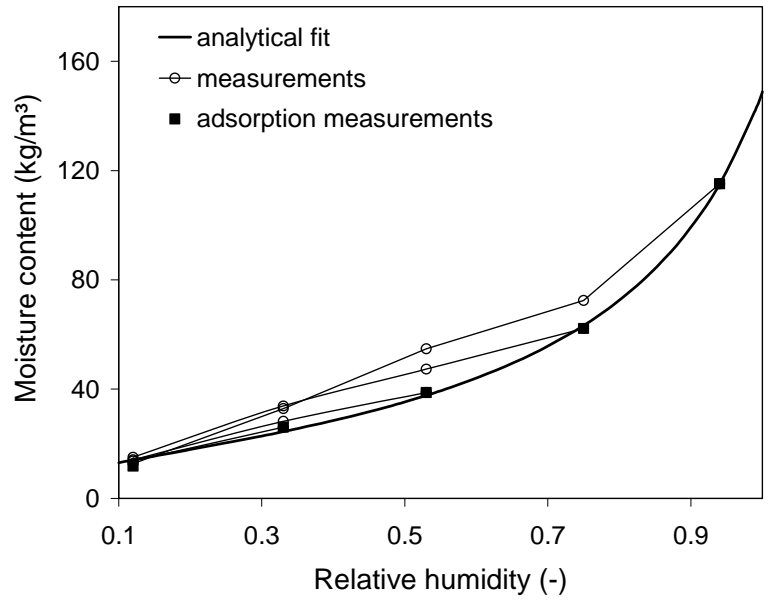

Figure 4. Main adsorption and primary desorption data for telephone book (TB) paper (a) and magazine (M) paper (b). Thick solid line: analytical fit of main adsorption isotherm. 
(a)

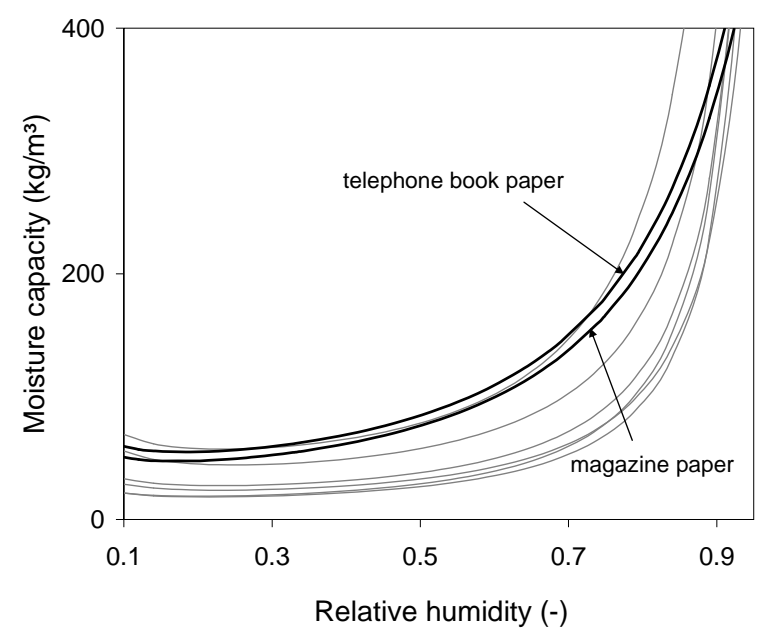

(b)

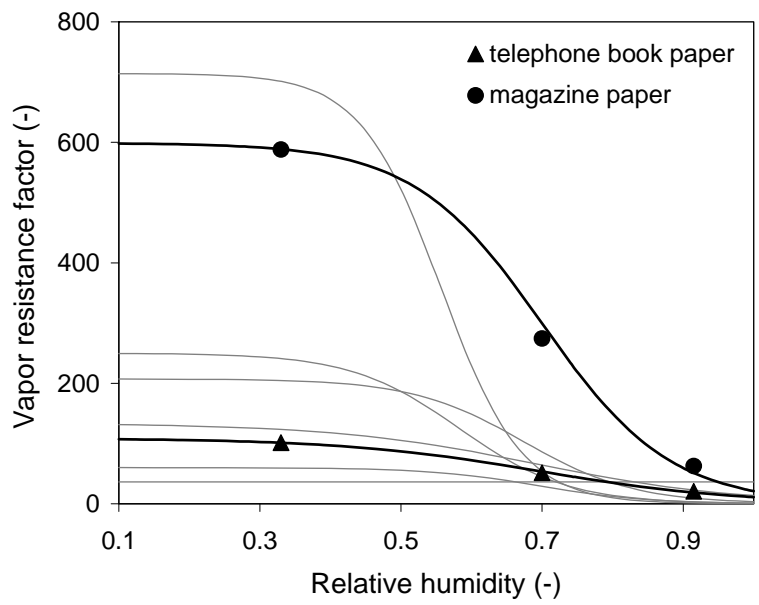

Figure 5. Moisture capacity (a) and vapor resistance factor (b) of telephone book (TB) paper and magazine (M) paper compared with literature data (in gray; for data specifications see Table 1 and 2). 
(a)

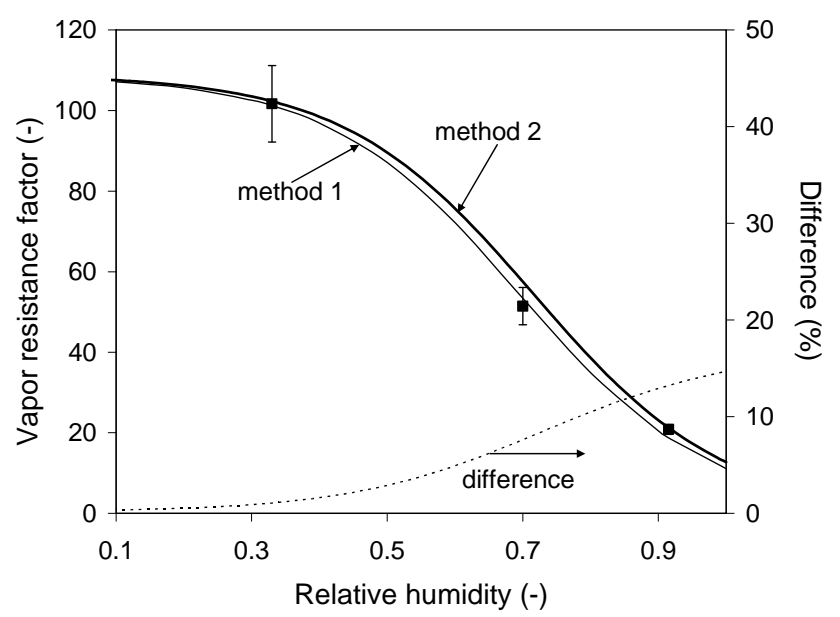

(b)

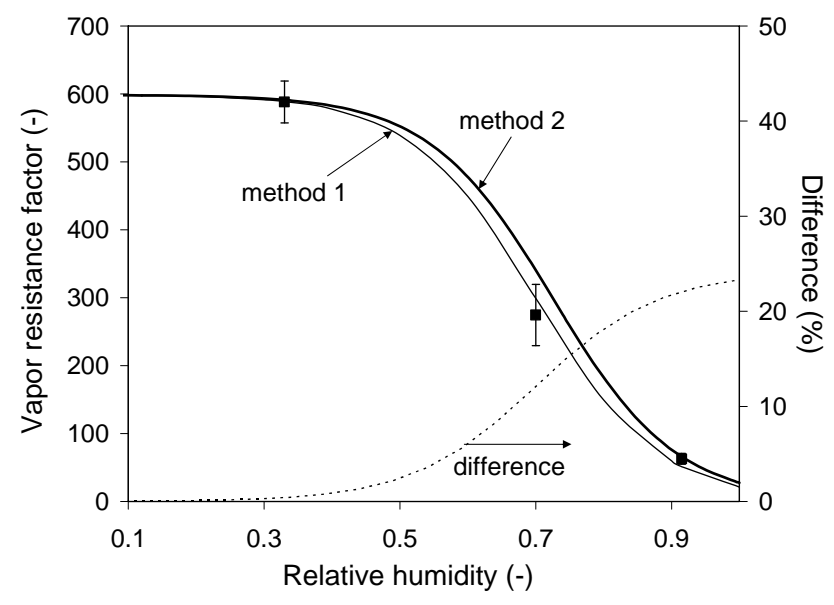

Figure 6. Vapor resistance factor of telephone book (TB) paper (a) and magazine (M) paper (b) determined by method 1 (Equation (6)) and method 2 (Equation (9)). 
(a)

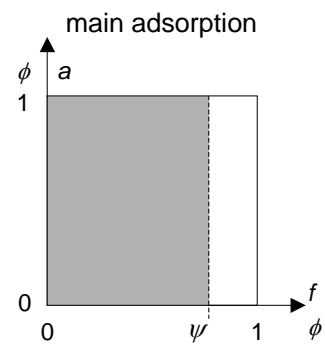

(b)

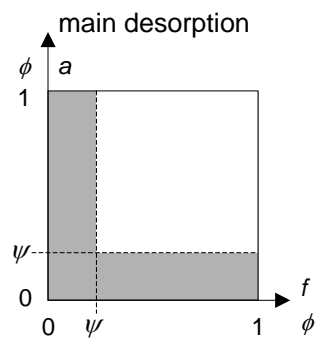

(c)

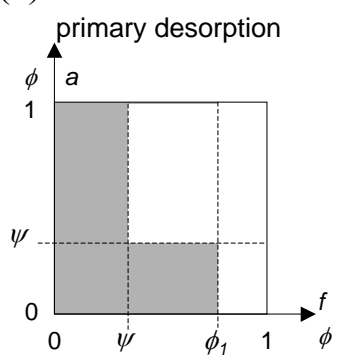

(d)

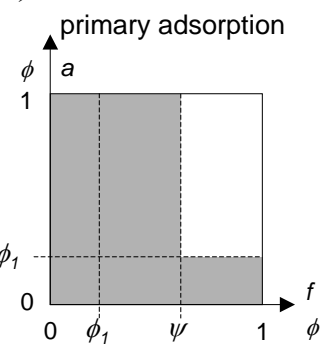

Figure 7. Main adsorption, main desorption, primary desorption , primary adsorption processes represented in the $f-a$ space, where $f$ represents the sorption sites and $a$ the accessibility function.

(a)

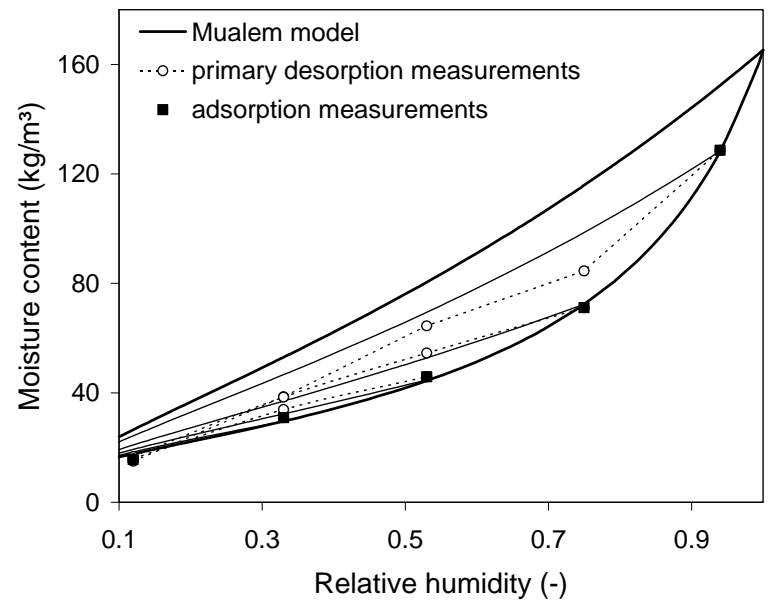

(b)

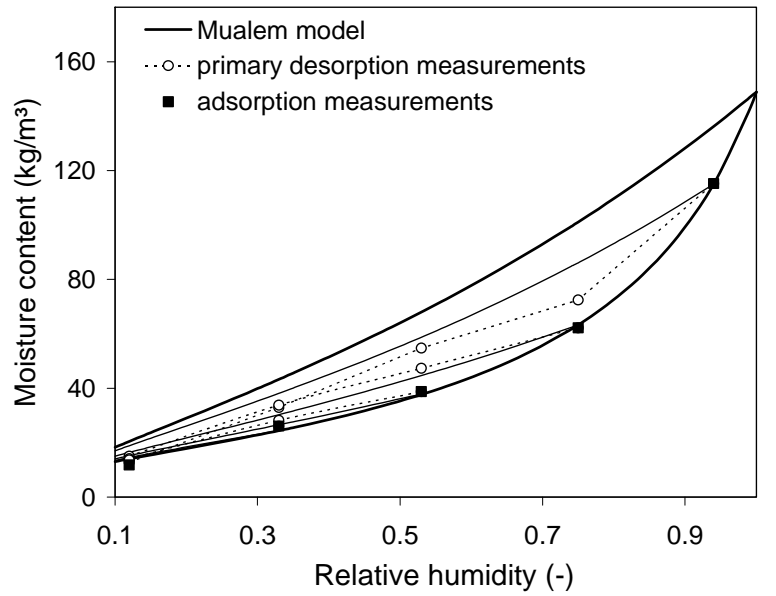

Figure 8. Comparison of measured primary desorption curves (bullets and dotted line) with model predictions (solid lines). Squares represent the measured adsorption curves. (a) telephone book (TB) paper and (b) magazine (M) paper. 


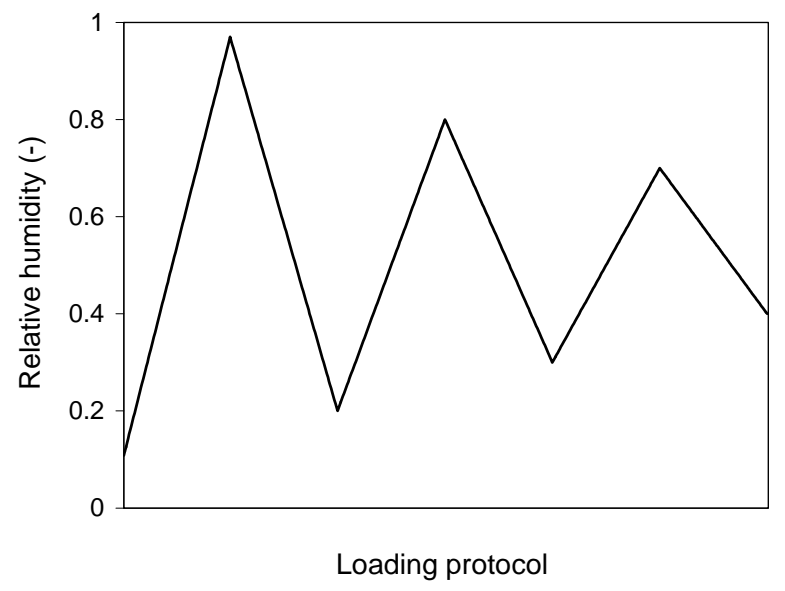

Figure 9. Relative humidity loading protocol. 
(a)

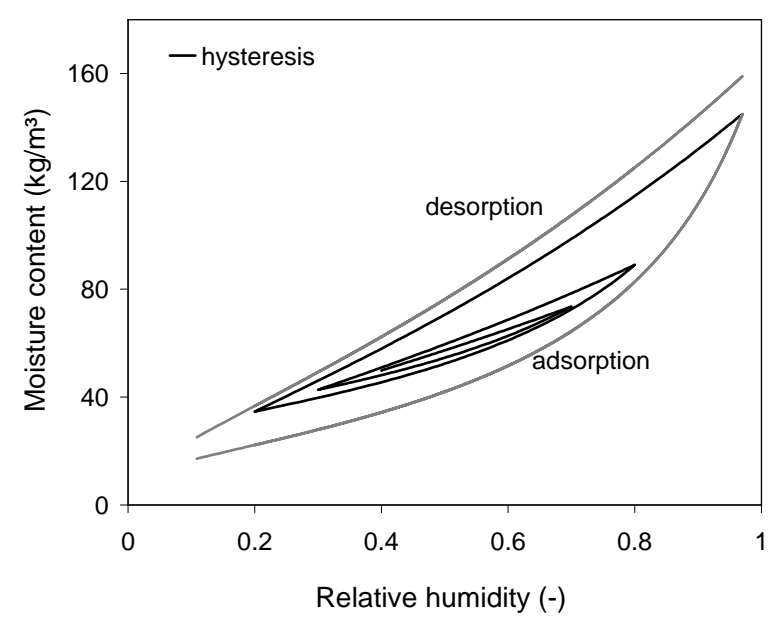

(c)

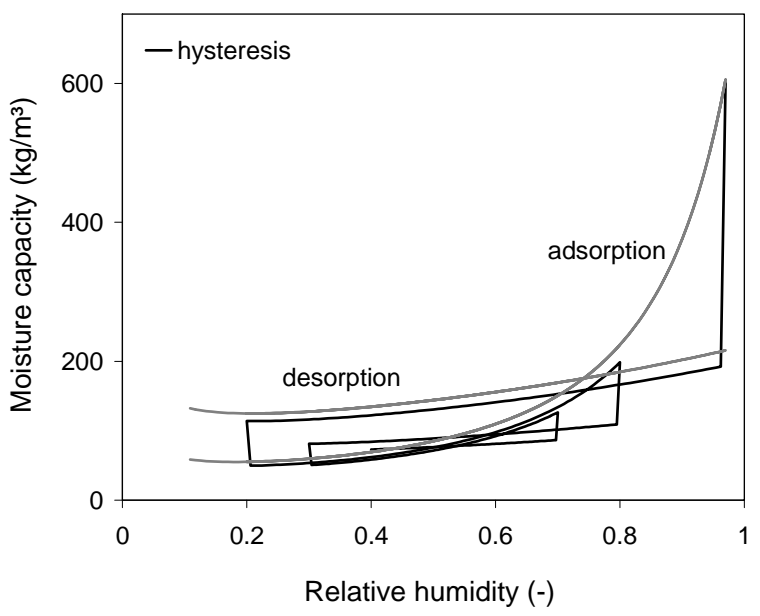

(b)

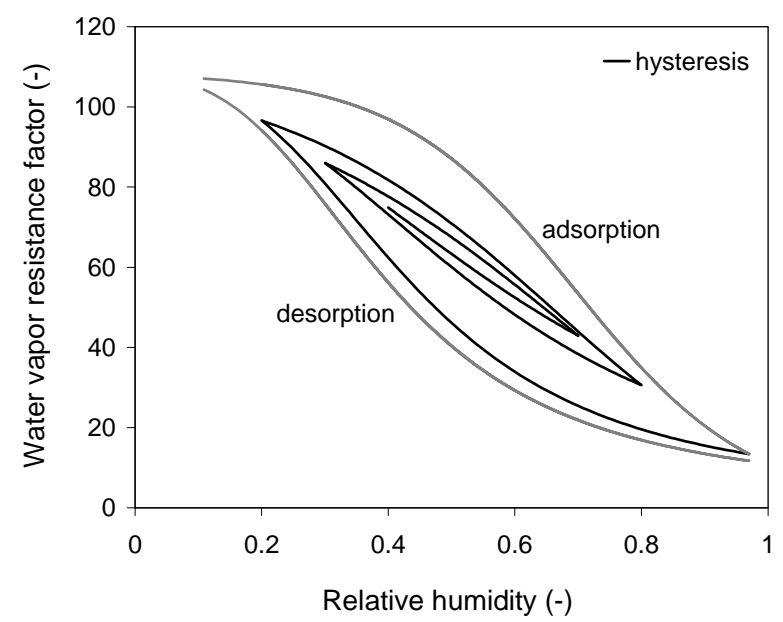

(d)

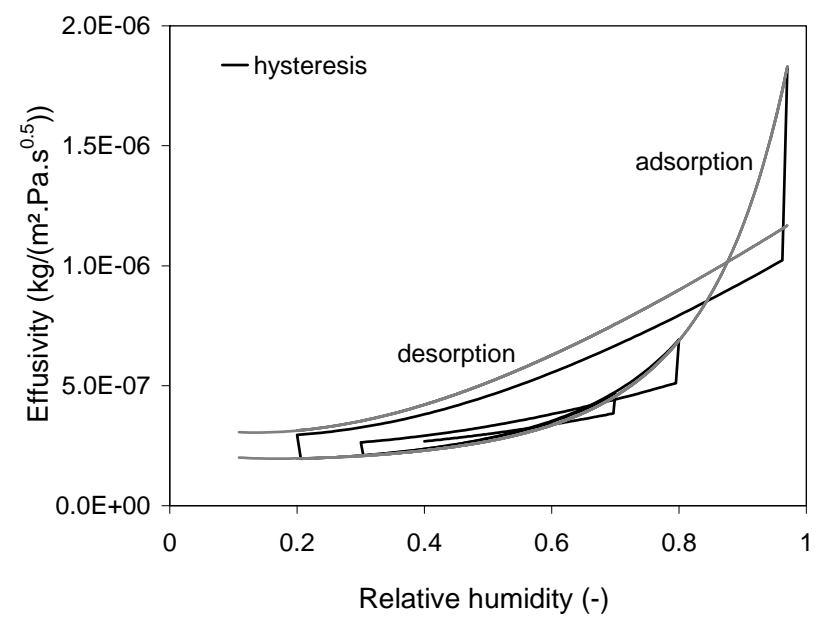

Figure 10. Hysteretic loops and main adsorption and desorption curves of loading protocol for the sorption isotherms (a), water vapor resistance factor (b), moisture capacity (c) and effusivity (d). 
(a)

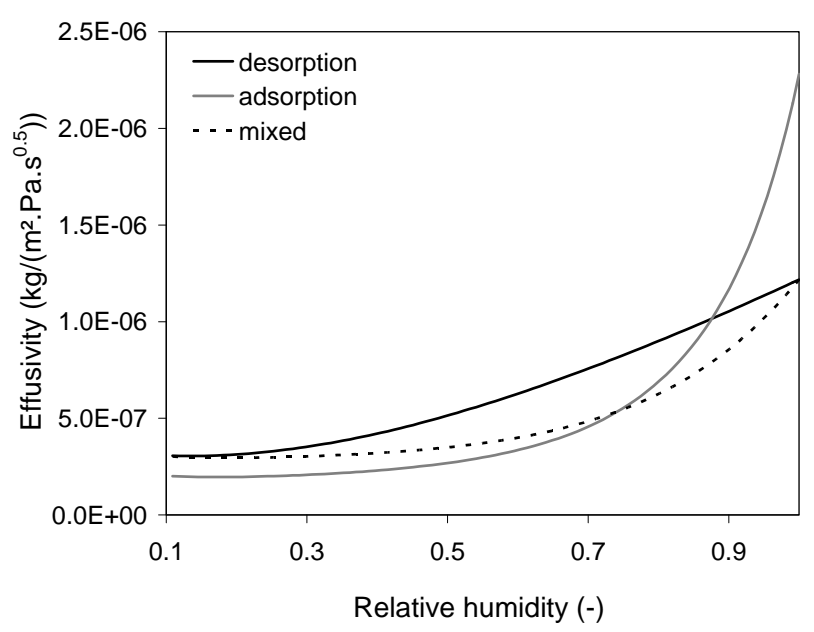

(b)

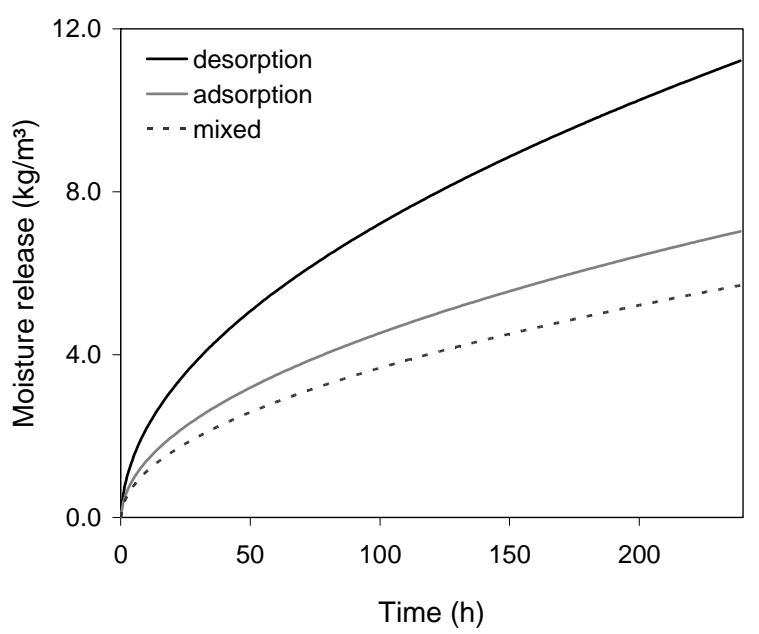

Figure 11. Effusivity (a) and moisture release (RH from 0.8 to 0.5 ) (b) of telephone book paper for three settings of paper properties. 
(a)

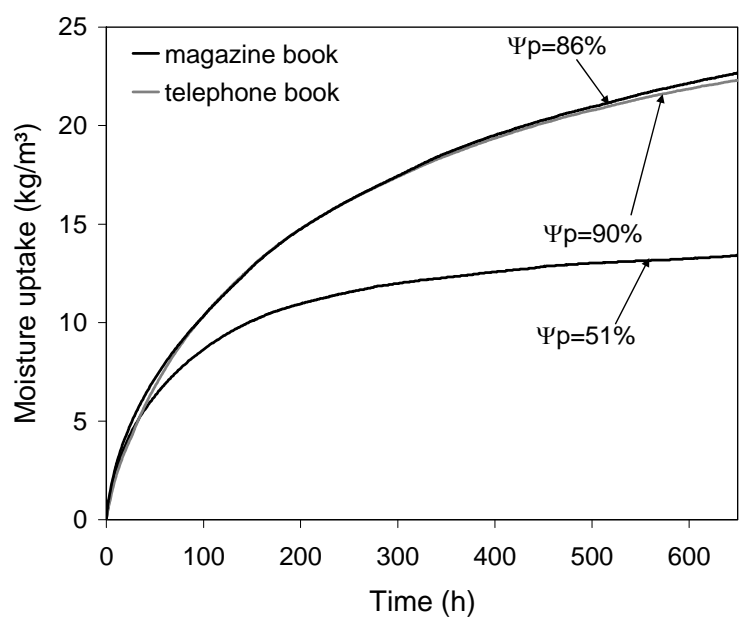

Figure 12. Moisture uptake by magazine and telephone book for different paper fractions. 


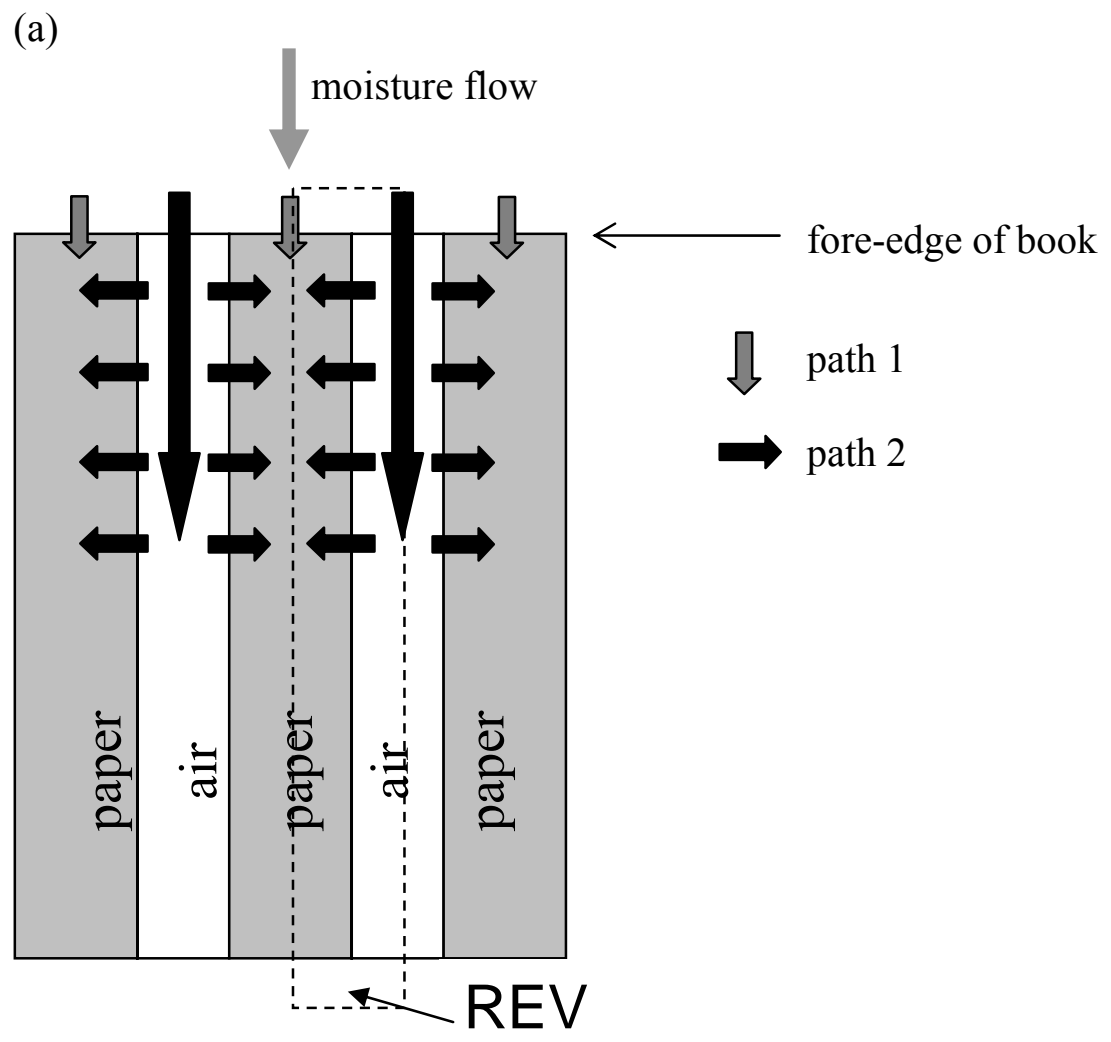

(b)

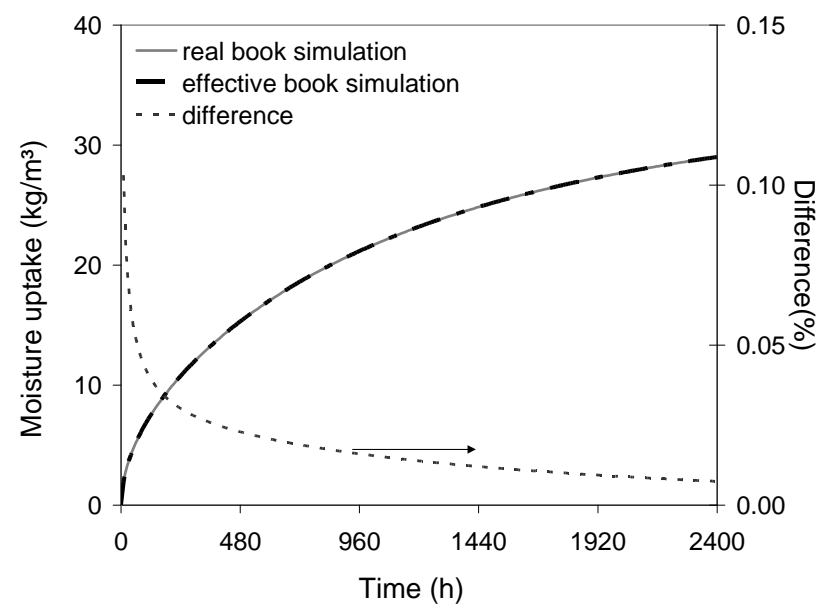

Figure 13. (a) Moisture transport paths in a book; (b) real and effective telephone book simulation, $\Psi_{\mathrm{p}} 60 \%$. 


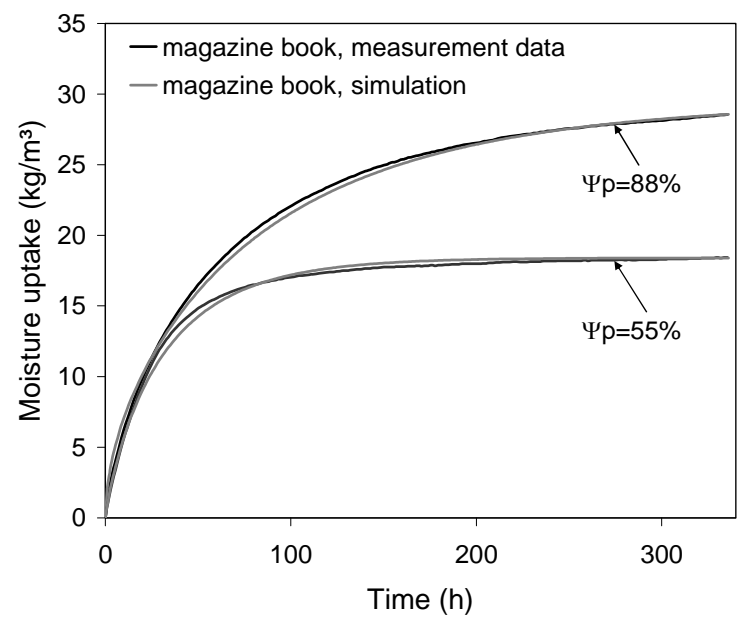

Figure 14. Simulating measured hygroscopic behavior of magazine book specimens with effective book model.

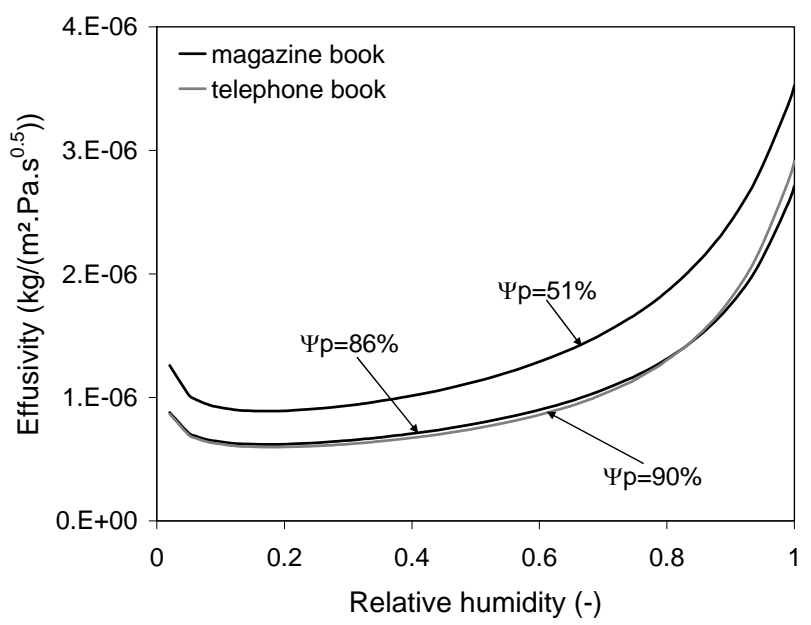

Figure 15. Effusivity of magazine book and telephone book in adsorption. 